\title{
Entre Gritos e Silêncios: Uma Análise Audiovisual de Funny Games
}

\author{
Livia Sampaio \\ Mestranda do Programa de Pós- \\ Graduação em Comunicação e Cultura \\ Contemporâneas pela Universidade \\ Federal da Bahia ( UFBA ) na linha de \\ pesquisa em Análise. Possui graduação \\ em Ciências Econômicas pela PUC-RJ. \\ E-mail : Immsampaio@hotmail.com
}

Resumo: O presente artigo pretende fazer uma análise audiovisual do filme Funny Games (1997), escrito e dirigido por Michael Haneke, com especial atenção ao uso do som, por meio de música, diálogos e ruídos. Investigar as estratégias de combinação entre som e imagem, buscando identificar de que forma o som interfere e impacta a narrativa cinematográfica é fazer um percurso dentro da análise fílmica extremamente rico, considerando que se trata de um filme no qual o uso das diversas formas sonoras pontuam momentos impactantes, especialmente nas cenas onde as falas dos personagens são raras ou inexistentes. A metodologia utilizada estará centrada especialmente nas análises e teorias propostas por Michael Chion, Noel Burch, David Bordwell e Kristin Thompson, Claudia Gordman, Jaques Aumont e Michel Marie. Outros conceitos identificados durante a análise serão considerados.

Palavras-chave: Cinema; som; análise fílmica; cinema sonoro; Funny Games (filme).

Abstract: This article intends to make an audiovisual analysis of Funny Games (1997), written and directed by Michael Haneke, with special attention to the use of sound, through the music, dialogues and noises. It is an extremely rich route in film analysis to investigate the strategies of combination of sound and image, seeking to identify how the sound affects and impacts narrative film, and considering that is a film in which the use of various sonorous forms demarcates impactful moments, especially during scenes where the characters' speeches are rare or nonexistent. The methodology will focus especially on the analyzes and theories proposed by Michael Chion, Noel Burch, Bordwell and Thompson, Claudia Gordman, Jacques Aumont and Michel Marie. Other concepts identified during the analysis will be considered.

Keywords: Cinema; sound; film analysis; sound movies; Funny Games (film).

\section{Introdução}

Focalizando a crueldade em suas diversas formas físicas e psicológicas, os filmes de Michael Haneke apresentam ao espectador histórias perturbadoras, ausência de respostas, personagens ambíguos e inacessíveis, finais não felizes. Planos longos, câmera fixa, cortes abruptos, uso da metalinguagem e sons articulados de maneira original são características recorrentes em suas obras. $O$ uso insistente do silêncio combinado a sons diegéticos oriundos do rádio e da televisão, por exemplo, trazem peculiaridade à forma fílmica que constitui um objeto de estudo amplo e curioso. Em sua análise sobre os filmes de Haneke, a pesquisadora Lisa Coulthard (2012) afirma: 
${ }^{1}$ Tradução livre de "Characterized by a lack of non-diegetic music (and a restriction of diegetic music), an emphasis on noise, silence, and disruptive vocality, Haneke's use of film sound echoes the deliberate alienation that drives his visual forms. This audiovisual alienation is most apparent in the way in which his films eschew the facial close-up, a visual dominant that has auditory repercussions" (COULTHARD, 2012a: 89).

\footnotetext{
${ }^{2}$ Não há unanimidade sobre qual foi o primeiro filme sonoro, em relação à sincronia entre som e imagem, mas é mais frequente considerar The Jazz Singer como o pioneiro.

"The Jazz Singer, realizado em 1927 por Alan Crosland, ocupa um lugar único na História do cinema: foi o primeiro filme falado" disponível em <http://www. infopedia.pt/\$o-cantor-de-jazz> acesso em 04 nov 2013.

"O filme sonoro, ou seja, o longa metragem de ficção com som gravado, aparece a partir de 1926 e 1927 com Don Juan e The Jazz Singer (O Cantor de Jazz)" (AUMONT, MARIE, 2010: 277).
}

Caracterizada por uma falta de música não diegética (e uma restrição de música diegética), uma ênfase sobre o ruído, silêncio e vocalidade perturbadores, o uso que Haneke faz do som no cinema ecoa a alienação deliberada que impulsiona suas formas visuais. Esta alienação audiovisual é mais evidente na maneira em que seus filmes evitam o close-up facial, um dominante visual que tem repercussões auditivas ${ }^{1}$. (COULTHARD, 2012a: 89).

Funny Games (1997), seu quarto filme para o cinema, possui um enredo lacônico. Uma dupla de jovens entra na casa de campo de uma família - pai (Georg), mãe (Anna) e filho (Georg Jr.) - com um único objetivo: torturá-los até a morte. As ações com os cinco personagens ocorrem quase todo o tempo dentro da casa e as reviravoltas na trama advém muito mais dos recursos de encenação do que do texto em si. Por esta razão, este texto abordará especialmente a forma fílmica, distanciando-se, dentro do possível, do seu conteúdo textual. O ineditismo do conjunto da experiência estética articulada nesta obra provoca nos espectadores as mais diversas sensações e impressões fronteiriças, e o papel do som necessita de relevância para melhor compreensão do manejo entre sons e imagens.

Segundo os teóricos Jacques Aumont e Michel Marie (2004), "o olhar com que se vê um filme torna-se analítico quando, como a etimologia indica, decidimos dissociar certos elementos do filme, para nos interessarmos mais especialmente por tal momento, tal imagem, ou parte da imagem, tal situação" (AUMONT e MARIE, 2004: 12).

Os contrastes acústicos de Funny Games, que vão desde mudanças bruscas de volume, barulhos, gritos e outros ruídos até associações musicais abstratas - como o silêncio absoluto dos personagens ao som diegético de uma televisão, rádio ou CD - levam o espectador a construir em sua mente imagens não mostradas e caracterizam importantes paisagens sonoras desta narrativa.

Sem desconsiderar a relação direta entre som e imagem, as diversas formas de combinação dos sons utilizados em Funny Games serão priorizadas neste trabalho, inclusive por se tratar de um viés ainda pouco abordado em obras cinematográficas que não se alicerçam sobre a música.

O percurso metodológico será dará através do levantamento de alguns estudos que tratam do uso som no cinema, sua correspondência com as imagens apresentadas e seus entrelaçamentos com o filme abordado.

\section{Sobre o som no cinema}

Em seis de outubro de 1927 ocorreu em Nova lorque a avant première do filme $O$ Cantor de Jazz (The Jazz Singer), que estreou oficialmente em quatro de fevereiro de 1928. Embora o som já estivesse presente no cinema mudo, tanto ao vivo, através da figura do pianista e outras vezes da orquestra, quanto gravado - "uma junção bem precoce do fonógrafo com o cinematógrafo" (AUMONT e MARIE, 2010: 204) -, O Cantor de Jazz é considerado o primeiro filme falado da história do cinema, ou seja, o pioneiro no uso do som sincronizado com a imagem².

Deixando os espectadores encantados ao ouvirem a voz em sintonia com a imagem do ator Al Jolson na tela, a novidade causou polêmica entre cineastas e estudiosos do cinema que se alvoroçaram em apoios, rejeições e muitos questionamentos. Alguns, preocupados com o possível desvio da função desta arte, protestaram defendendo a continuidade do cinema mudo ou propondo outras utilizações para o som no cinema. Não houve indiferença. A chegada do som sincronizado foi um divisor de águas na sétima arte. 


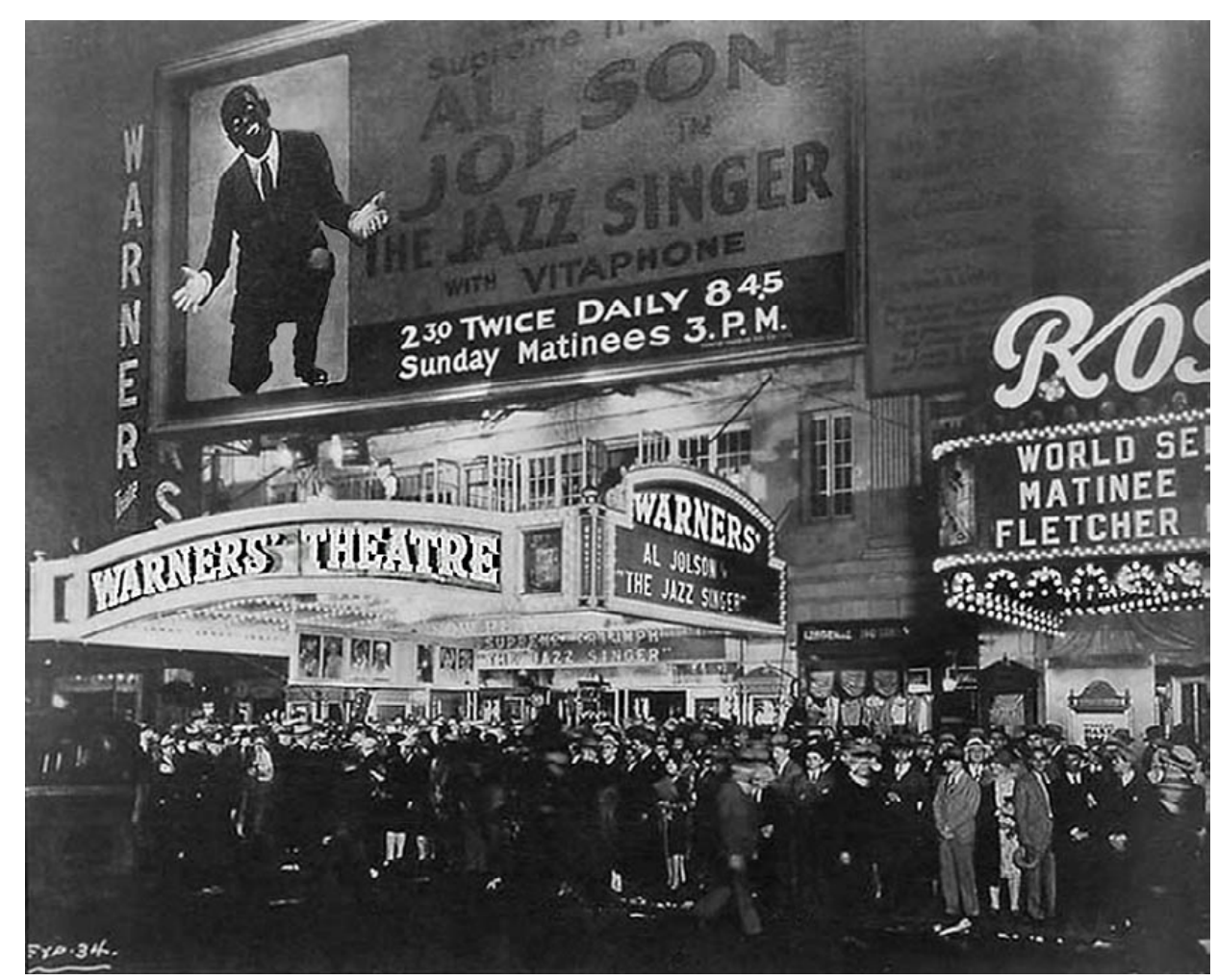

Figura 1 - The Jazz Singer - avant premiére

Fonte : Alt film guide. <http://www.altfg.com/blog/actors/the-jazz-singer-80thanniversary/>. Acesso em: 31out.2013.

Um marco neste início do cinema sonoro ocorreu em 1928, quando os cineastas russos Sergei Eisenstein, Grigori Aleksandrov e Vsevolod Pudovkin escreveram o manifesto Declaração sobre o futuro do cinema sonoro, no qual apoiavam a chegada do som sincronizado, com ressalvas, temendo o uso inapropriado da nova técnica.

${ }^{3}$ Tradução livre de "The dream of a sound film has come true [....]. At the same time we consider it a opportune to state a number of principal premises of a theoretical nature, for in the accounts of the invention it appears that this advance in films is being employed in an incorrect direction. Meanwhile, a misconception of the potentialities within this new technical discovery may not only hinder the development and perfection of the cinema as an art but also threaten to destroy all this present formal achievements" (EISENSTEIN, PUDOVKIN E ALEXANDROV apud WEIS e BELTON, 1985: 83)
O sonho de um filme sonoro se tornou realidade [.....]. Ao mesmo tempo nós consideramos oportuno mencionar algumas premissas principais de natureza teórica que devem ser contabilizadas neste invento que parece ser um avanço em filmes, mas pode estar sendo empregado no sentido errado. Enquanto isso, um equívoco sobre o potencial dessa nova descoberta pode não somente obstruir o desenvolvimento e perfeição do cinema como uma arte, mas pode também ameaçar destruir todas as suas atuais conquistas formais." 3 (EISENSTEIN, PUDOVKIN E ALEXANDROV apud WEIS e BELTON, 1985: 83).

Fato é que o cinema sonoro veio para ficar. Até os dias atuais, alguns estudiosos questionam se é bom ou não. Michel Chion, no capítulo sete do seu livro $A$ Audiovisão (2008), dá ao primeiro tópico o título Sessenta Anos de Lamentos, lembrando que a história do som no cinema foi quase sempre contada através da ideia de uma divisão entre cinema mudo e cinema falado, mas que "para além da história visível descontínua do cinema, marcada por acontecimentos referenciáveis [....], prossegue uma história contínua, feita de mudanças mais ou menos progressivas e mais difíceis de deletar" (CHION, 2008: 114 ).

Chion denominou de síncrese a combinação entre sincronismo e síntese. Para o autor, a síncrese abriu as portas do cinema sonoro, pois foi através deste efeito que as configurações audiovisuais tornaram-se mais ricas. Ele define o ponto de sincronização no audiovisual como um encontro síncrono entre um momento sonoro e um visual, afirmando que "o ponto de sinconização é, com efeito, o lugar onde o arco audiovisual encontra o solo e se eleva de novo" (CHION, 2008: 52). Lembra que a combinação entre som e imagem, hoje natural para o cinema, construiu-se em um espetáculo à época. Um dos caminhos que o autor coloca para melhor observar a estrutura de som e imagem de um filme é o que 
ele denominou de "método de máscaras", que propõe assistir várias vezes uma sequência, observando-a com o som e a imagem sincronizados, outras vezes só com o som, e outras só com a imagem.

A função do som de pontuar uma cena no cinema é enfatizada por Chion. Remetendo à encenação no teatro, o autor faz um breve histórico do significado de "pontuar cenas", seja através de pausas, respiração, gestos e outras expressões, ou através das múltiplas pontuações no cinema mudo: gestuais, visuais, inclusive dos cartões que funcionaram como um novo elemento de pontuação. A chegada do som sincronizado possibilitou ao cinema "um meio mais discreto e sub-reptício de o introduzir nas cenas sem carregar o desempenho dos atores ou a planificação" (CHION, 2008: 44).

O crítico e teórico de cinema André Bazin (2012), maior expoente do pensamento realista no cinema, ressaltou o progresso do realismo cinematográfico através das novas perspectivas sobre a estética do cinema ligadas ao avanço tecnológico que incluíam o som e, posteriormente, as cores. Para Bazin, os valores do cinema mudo persistiram no cinema sonoro, não havendo oposição entre as duas cinematografias, mas sim a convergência entre aspectos dos dois grupos com seus estilos e concepções cinematográficas fundamentalmente diferentes.

Em seu trabalho Fundamental Aesthetics of Sound, David Bordwell e Kristin Thompson (apud Weis e Belton, 1985), discorrem sobre os poderes do som, suas propriedades acústicas - sonoridade, potência, timbre -, e algumas combinações possíveis entre som e imagem cinematográfica. Segundo os autores, o som no cinema possui três formas: fala, música e ruídos (ou efeitos sonoros), sendo que, ocasionalmente, um som pode conter estas três categorias, deixando aos cineastas a possibilidade para explorarem estas ambiguidades.

Claudia Gorbman (1980; 1987), outro destaque entre os autores que estudam as funções da música no cinema, elaborou diversos estudos, inclusive sobre as funções do silêncio na narrativa cinematográfica. Para a autora, a música no cinema narrativo tem como função principal envolver emocionalmente o espectador, inserindo-o no filme, levando-o inclusive a esquecer da natureza tecnológica da narrativa.

Ainda nos estudos do som no cinema, Noel Burch (1992) dedica um capítulo do seu livro Práxis No Cinema à utilização estrutural do som, destacando, assim como outros autores citados, que "ao falar das inter-relações entre os materiais sonoros e entre o espaço sonoro e o espaço visual, referimo-nos tanto à música como aos diálogos e ruídos, porque achamos que esses dois tipos de interação dialética podem envolver todos os elementos sonoros" (BURCH, 1992: 120).

É inegável, portanto, que os estudos do som no cinema não se limitam aos estudos da música no cinema. Quando se fala em analisar o som na narrativa cinematográfica, é imperativo considerar o significado que a palavra "som" abarca, especialmente no caso de filmes de gênero não musical, ou, como Funny Games, que faz pouquíssimo uso da música, mas utiliza diversos elementos sonoros, como ruídos e silêncio.

Segundo Jacques Aumont e Michel Marie,

O som que um filme oferece raramente intervém sozinho. Ele supõe um agenciamento entre vários eixos: ruídos, falas e, às vezes, música. Procede de uma certa arte da composição sonora. Além disso, o som fílmico é acompanhado de uma percepção visual, até mesmo nos casos-limite em que a tela fica escura. A percepção fílmica é, portanto, áudio (verbo) visual e faz intervir numerosas combinações entre sons e imagens: redundância, contraste, sincronismo ou dessincronismo ou dessincronização etc. (AUMONT, MARIE, 2010: 276). 


\section{Ouvindo Funny Games}

Em The violence of silence: Vocal provocation in the cinema of Michael Haneke, Lisa Coulthard observa que nos filmes de Michael Haneke:

[.....] uma uniformidade de estilo é facilmente identificável e é uma identidade formal formada em grande parte por tendências acústicas: poucos diálogos, raros casos de música que estão sempre, de alguma forma diegeticamente motivados e uma enorme amplitude dinâmica que muda de

${ }^{4}$ Tradução livre de " .... a uniformity of style is readily identifiable and it is a formal identity shaped in large part by acoustic tendencies: minimal dialogue, only rare instances of music that are always in some way diegetically motivated, an intensification of foley sounds associated with bodily movement and a massive dynamic range that shifts abruptly and violently between noise and silence (COULTHARD, Lisa., 2012a: 19)

${ }^{5}$ Também chamada de trilogia da Incomunicabilidade, composta pelas obras Código Desconhecido (1989), seu primeiro filme para o cinema; Benny's Vídeo (1992) e 71 Fragmentos Cronologia do Acaso (1994).

${ }^{6}$ Disponível em < http://www. cinemaemcena.com.br/plus/modulos/ filme/ver.php?cdfilme $=5370>$. acesso em 01 nov. 2013.

Com um enredo simples, no qual dois psicopatas (Peter e Paul) entram na casa de férias de uma família e fazem uma aposta - com a família e com o espectador de que pai, mãe e filho estarão mortos até a manhã do dia seguinte, Funny Games consagra o estilo do diretor em contar histórias. Mantendo as características da construção narrativa dos seus três primeiros filmes que compõe a chamada "Trilogia da Era Glacial" silêncios, pouca música e mídia gravada utilizada como som diegético - televisão, vídeo cassete, CD's, DVD -, "a história do longa não importa de fato, já que é empregada apenas para permitir que Haneke se entregue a um exercício narrativo que explora e condena, simultaneamente, o maniqueísmo do gênero e do cinema de modo geral", como descreve o crítico de cinema Pablo Villaça ${ }^{6}$.

Este exercício narrativo é justamente a forma que o diretor utiliza ao apropriar e manejar técnicas de encenação para causar efeitos no espectador. Segundo o Prof. Dr. Wilson Gomes,

Na obra de arte a intervenção do criador estabelece os meios e os modos que a potencializa deste ou daquele modo, em suma, que orientam a sua realização, a sua atualização. O criador, o autor é um destinador, um programador da destinação e, por conseguinte, da realização da obra. Nesse sentido, uma obra expressiva é sempre uma composição de estratégias destinadas a configurar a apreciação, a determinar, portanto, aquelas circunstâncias onde as possibilidades vêm à realidade. A perspectiva de todo autor e de toda obra, portanto, é o de que a apreciação pode ser programada (GOMES, 2004b: 98).

Trazendo este conceito de apreciação programada para a análise audiovisual de Funny Games, é legítimo afirmar que o som neste filme dá o tom da obra.

O primeiro minuto e meio de projeção apresenta a família que percorre em seu carro uma bucólica e ensolarada estrada. Toda cena é construída para levar ao espectador a ideia de que ali está uma família feliz em férias. Eles estão alegres, a estrada é bela, o dia está lindo e os pais, sob o olhar atento e admirado do filho, brincam de adivinhar nomes de músicas clássicas que tocam no CD do carro. Eles não brincam de adivinhar palavras. Brincam de adivinhar as peças e intérpretes das músicas eruditas que escolhem para ouvir. Händel, Mascagni e Mozart. O jogo musical, sábio e gracioso, apresenta personagens que, além de felizes e abastados, são cultos. Esta sequência harmônica é quebrada, apenas para o espectador, quando estouram na tela os créditos do filme em grandes letras vermelhas que lembram os filmes de terror tipo $B$, ao som dos acordes caóticos de "Bonehead" música do compositor e saxofonista John Zorn. A tranquilidade mantém-se no interior do carro. Os personagens continuam harmônicos como a música clássica que ouvem, mas para a plateia é elaborada outra cena. As letras vermelhas e, especialmente, a troca repentina da música, abalam a sensação do êxito da estabilidade pretendida pela família e proposta até então.

Esta sequência inicial é construída através uma justaposição de imagens - a família no carro e os créditos em letras grandes e vermelhas - e de som, mas 
${ }^{7}$ Tradução livre de "the music that plays while a film's credits unroll - activates these cultural codes, and can reveal before-hand a great deal about the style and subject of the narrative to come" (Gorbman, 1980: 185). é o contraste entre a música clássica, melódica e os gritos de Zorn que impacta a narrativa. Segundo Claudia Gorbman "a música que toca enquanto aparecem os créditos do filme - jazz, pseudo-classical, Wagnerian, folk - ativam códigos culturais e podem revelar de antemão, muito sobre o estilo e o tema da narrativa que está por vir"7 (GORBMAN, 1980: 185). Utilizando o "método de máscaras" proposto por Chion, é fácil identificar a importância da análise sonora. Se tirarmos o som e ficarmos somente com as imagens da abertura de Funny Games, a justaposição das duas cenas perde praticamente todo o sentido, pois é a troca repentina da música que sinaliza a ambiguidade proposta.

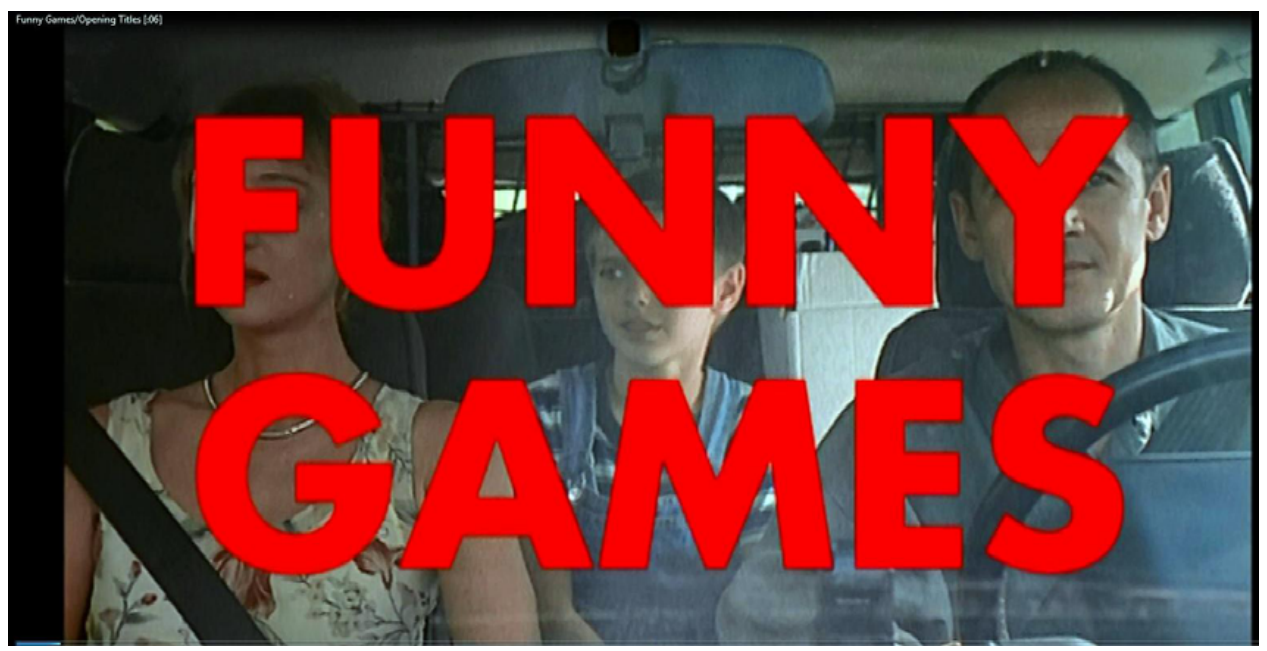

Figura 2 - Funny Games. Créditos Iniciais.

Fonte : HANEKE, Michael. Funny Games. [Filme-vídeo] 1997

Cabe, nesta análise, uma observação sobre a música de John Zorn ${ }^{8}$. Compositor, saxofonista, fundador do Theatre of Musical Optics, em Nova York, Zorn toca jazz, música clássica, rock experimental entre outros gêneros e é vocalista da banda Naked City que acompanha a música cantada por Zorn neste filme. Em algumas análises sobre Funny Games, é corriqueira a referência ao "trash metal de John Zorn", equivocadamente, segundo Haneke. Para o autor,

\begin{abstract}
Não é heavy metal. John Zorn não faz heavy metal. Assim como o filme é uma paródia de um thriller clássico, John Zorn é uma paródia de heavy metal clássico. A música clássica não é a trilha sonora deste filme. Toda a minha música não deve ser entendida como uma parte da trilha sonora é sim a ação, que faz parte da história. A outra música, a música de John Zorn, está sob os títulos, e é o cólon irônico. OK, agora vamos para um thriller ${ }^{9}$
\end{abstract}

A música Zorn aparecerá novamente no filme quando Paul, um dos sequestradores, persegue Georg Jr., que fugiu para a casa de um vizinho. Já próximo a Georg Jr., Paul diz "Vem cá. Vou colocar uma música para nós”, e põe para tocar Hellraiser, que traz os mesmos gritos, o mesmo incômodo acústico que a música de abertura. Bonehead e Hellraiser, embora sejam faixas separadas do álbum Torture Garden, do grupo Naked City - uma compilação de miniaturas hardcores ${ }^{10}$-, possuem algumas gravações conjuntas, como se fossem uma única música ${ }^{11}$. Aqui, a música pontua o inegável controle de Paul sobre a situação. Ele persegue Georg Jr., sabe que será fácil acuá-lo, permite que Georg Jr. aponte o rifle para ele e ainda avisa-o de que deve puxar o gatilho. Assim como controla a música, Paul controla a cena. Ele sabia que a arma estava descarregada. Ao som de Naked City, a perseguição finda quando o tiro não sai. Paul olha para Georg Jr. e sussurra sarcasticamente "pufff". Tocada pela banda Naked City, com John Zorn no vocal. Álbum Torture Garden. Disponível em <http://www.youtube. com/watch?v=|AvMqwmnWCO $>$. Acesso em: 01 nov 2013. 


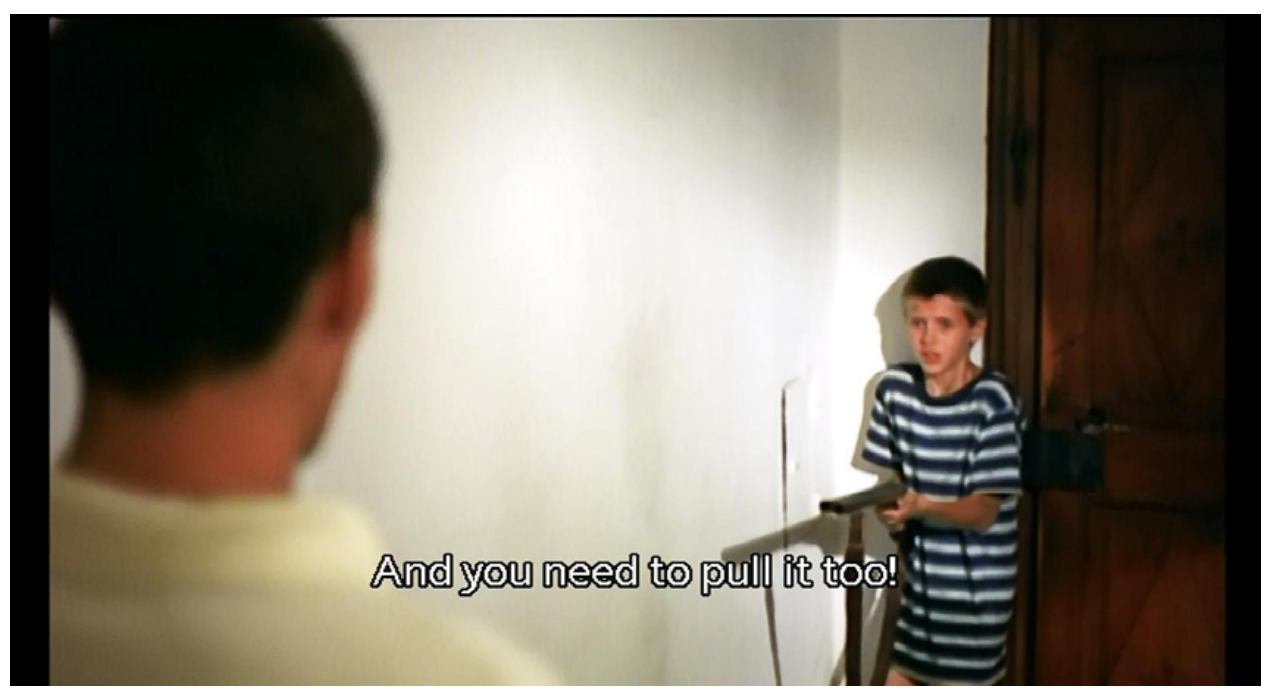

Figura 3 - Funny Games. Paul e Georg Jr.

Fonte: HANEKE, Michael. Funny Games. [Filme-vídeo] 1997

Na sequência final do filme, Paul, já na casa da próxima vítima, olha para a câmera e, ao surgirem os créditos finais - também em letras vermelhas - volta a tocar a música da abertura. A narrativa circular - quando final do filme reencontra o início formando um o arco narrativo que fecha um círculo - indica que a história macabra recomeçará.

As músicas clássicas tocadas na abertura, as duas músicas de John Zorn e uma canção que toca no rádio pouco antes de Paul entrar na casa, compõem o universo musical do filme. Todas, combinadas com as imagens, possuem funções pontuais na trama, no sentido colocado por Chion. Até a música pop que toca no rádio discretamente enfatiza a cena na qual Anna lava as verduras na cozinha, tentando relaxar após a desastrosa chegada de Peter. Esta canção, quase inaudível, acompanha toda a cena em que Peter e Paul iniciam, em parceria, os primeiros diálogos com Anna.

Assim como o contraste que aparece entre a música clássica e o "metal" de John Zorn no início do filme, Funny Games segue com grandes diferenças acústicas. Falas, músicas e ruídos são muitas vezes abruptamente interrompidos por cortes, com longas pausas sonoras.

Destaca Chion que:

Para além do seu papel narrativo (apresentar ou lembrar o quadro de ação e as suas dimensões), o elemento de cenário sonoro pode ser também, graças à montagem, um papel pontuativo. A inteligência da sua distribuição no ritmo da cena pode renovar-Ihe e transfigurar-Ihe completamente a utilização (CHION, 2008: 49).

O uso do que se chama "espaço fora do quadro", ou seja, as cenas sugeridas que não vemos na tela, é marcante também. Grande parte dos atos violentos cometidos durante o filme não aparecem nos quadros. Ao espectador só é permitido ouvir sons, gritos, choro, mas ele não assiste ao "espetáculo" da violência. Burch (1992), afirma que para se compreender a natureza do espaço fílmico é fundamental entender que este espaço torna-se, na verdade, dois: aquele que está dentro do quadro e o que está fora do quadro. Haneke coloca a violência, mas nega ao espectador o acesso visual a ela que se dá pela audição.

Praticamente nenhuma imagem dos atos sanguinários é mostrada. É possível ouvi-los. A câmera mostra o desenrolar das ações que culminam em violência, mas no momento em que um personagem é morto, por exemplo, a câmera é desviada. O grau do sofrimento físico dos personagens é mostrado através dos seus gritos, ou seja, dos efeitos sonoros. 
${ }^{12}$ Chion divide o valor acrescentado pela música (e/ou ruídos) com o propósito de criar emoções específicas no cinema em "efeitos empáticos" e "efeitos anempáticos". Os empáticos ocorrem quando acrescentam diretamente emoções à cena, e os anempáticos quando manifestam uma indiferença em relação à situação mostrada (CHION, 2008: 14)

\footnotetext{
${ }^{13}$ Tradução livre de "On a primary
} level this relates to how the spectator perceives the image itself: the practically static tem-minutes take leads the spectator to examine the image visually on an aesthetic and intellectual level, rather than to "scan" the image mentally in order to place it within the context image, coupled with the lack of narrative drive, create awareness in the spectator of themself as a spectator. As the director put it, the reduction of montage to a minimum tends to shift responsibility back to the viewer in that more contemplation is required" (WHEATLEY, 2009: 93).
Uma longa tomada, com a câmera fixa por mais de dez minutos, é um exemplo memorável de combinação entre imagens, sons e silêncio. Após assassinarem Georg Jr., Peter e Paul saem da casa, deixando Anna e Georg sozinhos na sala. Anna está amarrada, e Georg, ferido desde o início do filme, continua imobilizado no chão. Esta cena pode assim ser dividida:

1. Durante um minuto e dez segundos a câmera fixa mostra o corpo caído de Georg Jr, de Anna, ajoelhada e atônita, e de Georg, mostra somente os seus pés. O único som é o da televisão que continua ligada, sintonizada em um canal no qual está passando uma corrida de carros, no qual mais se ouve do que se vê.

2. Com a boca, Anna desliga a TV. Mais de um minuto se passa mostrando Anna praticamente imóvel em um silêncio total.

3. Anna fala para Georg que os assassinos foram embora.

4. Três minutos de silêncio novamente até Georg começar a chorar e a gritar.

5. Mais quatro minutos deste plano mostram Anna e Georg abraçados. Georg tenta ajudar Anna a desvencilhar as mãos amarradas.

São mais de dez minutos com a câmera fixa, em que as falas são praticamente balbucios e o som é inexistente. Ouvimos apenas, no início, o som da corrida de carros que vem da televisão, os ruídos anempáticos ${ }^{12}$, assim nominados por Chion. Em sua análise sobre esta cena, a pesquisadora Catherine Weathley afirma:

Em um nível primário, isso se relaciona com a forma como o espectador percebe a própria imagem: os praticamente dez minutos estáticos levam o espectador a examinar a imagem visual em um nível estético e intelectual ao invés de "varrer" a imagem mental, a fim de colocá-lo dentro do contexto da narrativa. Mas em um nível secundário, a duração prolongada da imagem, associada à inexistência de uma unidade narrativa, cria consciência no espectador da si mesmos como um espectador. Como o diretor colocou, "a redução da montagem ao mínimo tende a transferir a responsabilidade de volta para o espectador em que mais contemplação é necessária ${ }^{13}$.

Chion lembra que, como apontou Bresson, foi o cinema sonoro que trouxe o silêncio. A interrupção de vozes e ruídos definiu o que denominamos de silêncio no cinema. "a impressão de silêncio numa cena de filme não é o simples efeito de uma ausência de ruído; só se produz quando é trazido por todo um contexto e toda uma preparação [.....] o silêncio nunca é um vazio neutro; [....]; é o produto de um contraste" (CHION, 2008, p. 50).

A ausência de som marca outras cenas de Funny Games, como quando Anna sai da casa para procurar ajuda na estrada. Momentos de silêncio alternados com sons de insetos noturnos, a respiração ofegante de Anna que caminha a passos rápidos, porém relutantes, são combinados com planos fixos e escuro quase total. O som de um carro que passa, com os faróis acesos na estrada silenciosa faz Anna se esconder. Ela não pede socorro. Teme que sejam os assassinos. Segundos depois, a cena se repete: outro carro, o som e a luz dos faróis. A cena é cortada e aparece Georg cobrindo o corpo do filho. O som de uma bola de golfe batendo no taco da casa anuncia que os rapazes voltaram. Com Anna imobilizada.

Toda esta cena é elaborada através de imagens e ruídos. Apenas duas pequenas frases são ditas quando Anna pede socorro e não há nenhuma música. Não é mostrada a imagem de Anna sendo capturada. Este momento de clímax é construído sem a imagem do ato. A sequência de imagens anteriores e posteriores, em conjunto com os efeitos sonoros, levam o espectador a construir a cena. O fato está posto: o jogo continua. 
Nos créditos finais de Funny Games, o contraste audiovisual é gritante, como a música de Zorn que volta a tocar. Após os créditos dos atores, em letras vermelhas, sobre o rosto de Paul que olha para a câmera - para o espectador - ao som em alto volume de Bonehead, a imagem e o som desaparecem. Na tela branca, rolam em silêncio os créditos restantes.
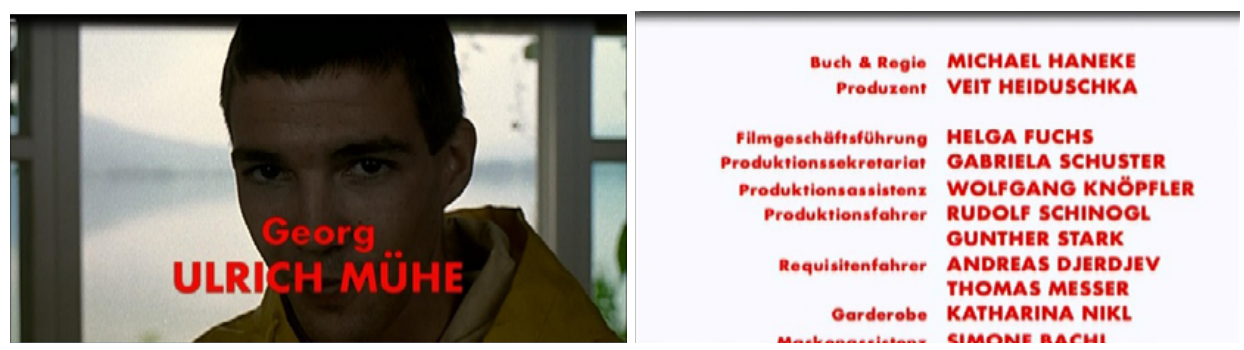

Figura 3 - Funny Games - Créditos finais (1) Figura 4 - Funny Games - Créditos Finais (2) Fonte: HANEKE, Michael. Funny Games. [Filme-vídeo] 1997.

\section{Considerações Finais}

A análise audiovisual, que busca compreender um filme sonoro através da combinação entre sons e imagens, deve, obviamente, considerar tanto o significado do som quanto o das imagens. Ocorre que algumas vezes, o estudo do som é minimizado, ainda que seja uma análise audiovisual. A intenção deste trabalho foi iluminar o papel do som.

Considerando que o som em um filme abarca tanto a música quanto as falas, ruídos, outros efeitos sonoros e até o silêncio, compreendê-lo além do papel que lhe é atribuído corriqueiramente - de sublinhar a narrativa - é fazer uma análise mais apurada.

Chion coloca com clareza a questão:

as consequências, para o cinema, são que o som é, mais do que a imagem, um meio insidioso de manipulação afetiva e semântica. Quer o som nos trabalhe fisiologicamente (ruídos da respiração); quer, pelo valor acrescentado, interprete o sentido da imagem e nos faça ver aquilo que sem ele não veríamos, ou que veríamos de outra forma (CHION, 2008: 33).

Econômicos nos diálogos, extravagantes na combinação entre sons especialmente ruídos e silêncios - e imagens, os filmes de Michael Haneke impactam, polemizam e marcam. Funny Games é uma obra na qual se pode explorar fartamente o uso dos efeitos sonoros que, sincronizados com as imagens, manipulam, sem ressalvas, as emoções dos espectadores.

A intenção deste artigo foi deixar clara a importância da análise audiovisual, especialmente dos efeitos sonoros. Ainda que não seja possível aqui, por falta de espaço, analisar mais detalhadamente todos os recursos sonoros utilizados em Funny Games, fica o registro de alguns pontos importantes que podem ampliar e enriquecer a análise fílmica.

\section{Referências bibliográficas}

AUMONT Jacques; MARIE, Michel. A Análise do Filme. Lisboa: Texto \& Grafia, 2004. . Dicionário Teórico e Crítico de Cinema. Campinas: Papirus, 2010.

BAZIN, André. ¿ Qué es el cine ? .Madrid: Ediciones Rialp, S.A, 2012. 
BURCH, Noël: Práxis do cinema. São Paulo: Perspectiva, 1969.

CHION, Michel. A Audiovisão: som e imagem no cinema. Lisboa: Texto \& Grafia, 2008.

CINEMA BLEND. Interview: Funny Games Director Michael Haneke, 12 mar. 2008. Disponível em: <http://www.cinemablend.com/new/Interview-Funny-GamesDirector-Michael-Haneke-8141.html>. Acesso em 20 nov. 2013. Tradução livre.

CINEMA EM CENA. Violência Gratuita. Crítica. Pablo Villaça, 20 set. 2008. Disponível em <http://www.cinemaemcena.com.br/plus/modulos/filme/ver. php?cdfilme=5370>. Acesso em 01 nov. 2013.

COULTHARD, Lisa. The violence of silence: Vocal provocation in the cinema of Michael Haneke, University of British Columbia, Vancouver: Studies in European Cinema, Vol. 9, Numbers 2 \& 3, p. 87-97. 2012

From a whisper to a scream: music in the films of Michael Haneke. Music and the Moving Image, University of Illinois, Chicago, Vol. 5, n. 3, p. 1-10. 2012.

GOMES, Wilson. Princípios da poética (com ênfase na poética do cinema). In: PEREIRA, M.; GOMES, R.C.; FIGUEIREDO, V.L.F. (Orgs.). Comunicação, representação e práticas sociais. Rio de Janeiro: PUC-Rio. 2004b, p.93-125

GORBMAN, Claudia. Unheard Melodies, Narrative Film Music. London: BFI Books, 1987. 183-203. 1980 .Narrative Film Music, Yale French Studies: Cinema/Sound, n. 60, p.

HANEKE, Michael. Funny Games. [Filme-vídeo] Produção de Michael Haneke, Direção de Michael Haneke, Áustria, Wega-Film, 108 min., Drama/ Thriller, 1997.

WEIS, Elisabeth; BELTON, John. Classical Sound Theory. In: WEIS, Elisabeth; BELTON, John (Orgs.). Film Sound: Theory and Practice. New York: Columbia University, 1985.

WHEATLEY, Catherine. Michael Haneke's Cinema: The Ethic of the Image. New York: Berghahn Books, 2009. 